\title{
Inactivation Efficiency of Escherichia coli and Listeria monocytogenes in Ground Pork by Combination of Natural Food Ingredients and High Pressure Processing
}

\author{
Samooel Jung, Hyejeong Yun, Hyun Joo Kim, Jun Sang Ham ${ }^{1}$ II Suk Kim², Mooha Lee ${ }^{3}$, and Cheorun Jo* \\ Department of Animal Science and Biotechnology, Chungnam National University, Daejeon 305-764, Korea \\ ${ }^{1}$ Quality Control and Utilization Division, National Institute of Animal Science, RDA, Suwon 441-706, Korea \\ ${ }^{2}$ Department of Animal Resources Technology, Gyeongnam National University of Science and Technology, \\ Jinju 660-758, Korea \\ ${ }^{3}$ Department of Food and Animal Biotechnology, Seoul National University, Seoul 151-742, Korea
}

\begin{abstract}
The objective of this study was to examine the effects of a combined treatment regarding antimicrobial food ingredients and high pressure processing (HP) on the inactivation efficiency of Escherichia coli and Listeria monocytogenes inoculated into ground pork. Ethanol extracted from garlic, leeks, onions, and ginger powder was prepared. Half of the prepared powder was irradiated at $5 \mathrm{kGy}$ to see the effect of pasteurization before addition. The prepared food ingredients were added into radiation-sterilized ground pork $(1 \%, \mathrm{w} / \mathrm{w})$, and inoculated with $E$. coli and L. monocytogenes. The samples were vacuumpacked and applied with HP at 0.1 (control), 300, 450, and $600 \mathrm{MPa}$. Microbial log reduction increased with the increase of pressure up to $600 \mathrm{MPa}$. With minor exceptions, overall efficiency of HP treatment with regards to inactivation of pathogens increased. Inoculated microorganisms showed approximately 7-8 Log reductions by $600 \mathrm{MPa}$, except for L. monocytogenes treated with garlic (5.7 Log reductions). The $E$. coli reduction in ground pork mixed with ethanol extracted garlic showed the highest efficiency (1.86) compared to leeks (1.25-1.31), onions (1.17-1.44), and ginger (1.50-1.82) when treated at an $\mathrm{HP}$ of $450 \mathrm{MPa}$. There was no evidence for the advantage of pasteurization concerning the food ingredients before addition of antimicrobial food ingredients and HP. Results demonstrate that the combination of antimicrobial food ingredients and HP treatment may help improve the efficiency of sterilization in meat systems.
\end{abstract}

Key words: food ingredients, pork, high pressure, combination

\section{Introduction}

Technological advances developed by the food industry have enabled the control of microbial hazards and reduction of foodborne diseases. Usually food preservation method used has been thermal processing including pasteurization and sterilization. However, theses processing affect sensory, textural, and nutritional qualities. Consumer demand is increasing for high quality, fresh tasting foods free from additives, microbiological safety, and extended shelf life (Leistner, 2000). Within this context the combination of hurdles to inhibit pathogen growth acquired high importance. Hurdle technology advocates

*Corresponding author: Cheorun Jo, Department of Animal Science and Biotechnology, Chungnam National University, Daejeon 305-764, Korea. Tel: 82-42-821-5774, Fax: 82-42825-9754, E-mail: cheorun@cnu.ac.kr the deliberate combination of existing and novel preservation techniques in order to establish a series of hurdles that no microorganisms present should be able to overcome (Leistner and Gorris, 1995).

High pressure processing (HP) is a non-thermal food preservation technology for inactivating post-processing contaminants, especially for foods whose nutritional, sensory and functional characteristics are thermo-sensitive (Marcos et al., 2008). HP kills and/or sub-lethally injures the cells by destroying the functionality of the cell wall and the cytoplasmic membrane, dissociating the proteins and the ribosomal subunit structures, and inactivating some enzymes (Hoover et al., 1989). Recently, HP is successfully applied on a commercial scale for pasteurization and available in world food market of a whole range of food products such as oyster and ham (Marcos et al., 2008; Prapaiwong et al., 2009). HP has also developed in combination with other technologies such as bacteriocin 
or other natural materials (Rastogi et al., 2007).

Several researchers found that microbial inactivation can be achieved efficiently by combining high pressure with heat or antimicrobial agents than by applying only HP (Marcos et al., 2008). Caillet et al. (2006) reported that the combination of natural materials with irradiation, another well-known non-thermal processing, increased the radiation sensitivity of bacteria. Yun et al. (2011) reported that food ingredients usually added into Korean processed meat products also increased the radiation sensitivity and increased inactivation efficiency. Such hurdle effect have many advantages in food processing including reduction of energy costs and the production of safer and more palatable products.

Therefore, the objective of this study was to examine the effect of combined treatment with natural antimicrobial food ingredients, ethanol extracted garlic, leek, onion, and ginger, and HP on inactivation efficiency of $E$. coli and L. monocytogenes inoculated into ground pork.

\section{Materials and Methods}

\section{Meat preparation and irradiation}

Ground pork was purchased from a local market in Daejeon, Korea and sealed into polyethylene pouch (2 $\mathrm{mL} \mathrm{O}_{2} / \mathrm{m}^{2} / 24 \mathrm{~h}$ at $0^{\circ} \mathrm{C}$, Sunkyung Co. Ltd., Korea). For the inoculation test of pathogens, samples were irradiated (35 kGy) in a cobalt-60 gamma irradiator (AECL, IR-79, MDS Nordion International Co. Ltd., Canada) at Advanced Radiation Technology Institute, Korea. The source strength was approximately $11.1 \mathrm{PBq}$ with a dose rate of $10 \mathrm{kGy} /$ $\mathrm{h}$ at $10 \pm 0.5^{\circ} \mathrm{C}$. Dosimetry was performed using $5 \mathrm{~mm}$ diameter alanine dosimeters (Bruker Instruments, Germany), and the free-radical signal was measured using a Bruker EMS 104 EPR Analyzer.

\section{Test pathogens preparation}

Escherichia coli (KCTC 1682) and Listeria monocytogenes (KCTC 3569) were obtained from a Korean Collection for Type Culture (KCTC, Korea). The strains were cultivated at $37^{\circ} \mathrm{C}$ for $18 \mathrm{~h}$ in a tryptic soy broth (Difco, Laboratories, SA), and $10 \mathrm{~mL}$ cultures of each strain were transferred aseptically to a $50 \mathrm{~mL}$ centrifuge tube and were vortexed for $10 \mathrm{~s}$. Each strain was centrifuged $\left(1,950 \mathrm{~g}\right.$ for $10 \mathrm{~min}$ at $\left.4^{\circ} \mathrm{C}\right)$ in a refrigerated centrifuge (VS-5500, Vision Scientific Co., Korea). The pellet was washed twice with sterile saline $(0.85 \%)$, and suspended in saline to a final concentration of approximately $10^{9} \mathrm{CFU} / \mathrm{mL}$ of the stock inoculum.

\section{Sample preparation}

Fresh garlic (Allium sativum L.), leek (Allium tuberosum R.), onion (Allium cepa L.), and ginger (Zingiber officinale) were purchased from a local market in Daejeon, Korea. Each sample (500 g) was extracted three times with $70 \%$ ethanol for $12 \mathrm{~h}$ in enclosed flask with constant shaking $(100 \mathrm{rpm})$ at room temperature. After filtration with a Whatman No. 2 filter paper, the residue was re-extracted with additional $200 \mathrm{~mL}$ of $70 \%$ ethanol for an additional for $12 \mathrm{~h}$ and then filtered. Ethanol was evaporated form the combined filtrates using a rotary evaporator (EYELA N-1000, Japan) at $50^{\circ} \mathrm{C}$. Then, it was freeze dried. Dried extracts were placed in sealed bottles and stored at $-20^{\circ} \mathrm{C}$ before use. The dried powders were dissolved in water $(10 \% \mathrm{w} / \mathrm{w})$ prior to use.

To see the effect of contamination of the ethnolextracted antimicrobial food ingredients, the half of the prepared food ingredients were irradiated at $5 \mathrm{kGy}$ as the same method previously described to reduce the original number of microorganisms present in the additives. The other half was used without irradiation.

\section{Inoculation of pathogens and high pressure treat- ment}

The prepared natural compounds, both irradiated at 5 $\mathrm{kGy}$ or none, were mixed with radiation-sterilized pork $(50 \mathrm{~g})$ at a concentration of $1 \%(\mathrm{w} / \mathrm{w}$, final concentration). The control sample without any additive was also prepared. The sample was sub-divided into portions each have $5 \mathrm{~g}$ in sterile polyethylene pouch bag $(8 \times 10 \mathrm{~cm})$, and inoculated with $L$. monocytogenes and E. coli. The test culture suspension $(50 \mu \mathrm{L})$ was uniformly and aseptically inoculated in different areas on the samples and mixed to achieve uniform dispersal at the desired concentration throughout the sample for $5 \mathrm{~min}$ in enclosed polyethylene bag. The bags were sealed and the inoculated samples were stored at $4^{\circ} \mathrm{C}$ for approximately $12 \mathrm{~h}$ prior to irradiation.

The samples were transported to the Korea Food Research Institute (Korea) in a cooled container and were subjected to treatment. Samples were placed in a pressure vessel submerged in hydrostatic fluid medium (Quintus food processor 6; ABB Autoclave Systems, Inc., USA) and pressurized at 300, 450, and $600 \mathrm{MPa}$ for $5 \mathrm{~min}$ with the initial temperature of the pressure vessel at $15 \pm 3^{\circ} \mathrm{C}$. Control samples were maintained under atmospheric pressure at $4^{\circ} \mathrm{C}$ while the other samples were treated. 


\section{Microbiological analysis}

Samples of HP treated were blended with sterile saline using a stomacher (BagMixer ${ }^{\circledR}$ 400, Interscience Ind., France) for $2 \mathrm{~min}$. Then, a series of decimal dilution was prepared with sterile saline and each diluent $(0.1 \mathrm{~mL})$ was spread in tryptic soy agar (Difco). The plates were incubated at $37^{\circ} \mathrm{C}$ for $48 \mathrm{~h}$ and microbial counts were expressed as Log CFU/g. HP efficiency ratio was determined ratio of reduced viable cell for HP treatment/control at $450 \mathrm{MPa}$.

\section{Statistical analysis}

Experiment was conducted as 3 independent trials with 2 observations for treatment combinations per each trial. Statistical analysis was performed by one-way Analysis of Variance (ANOVA), and when significant differences were detected, the differences among the mean values were identified by Student-Newman-Keul's multiple range test using SAS version 9.1 software (2002) with the confidence level at $p<0.05$. Mean values and standard error of the means are reported.

\section{Results and Discussion}

The initial number of total aerobic bacteria of ethanol extracted garlic, leek, and ginger were in the range of 1-3 Log CFU/g (data not shown). There was no viable cell detected in onion. When the ethanol-extracted food ingredients were irradiated at $5 \mathrm{kGy}$ for pasteurization, the number of total aerobic bacteria was not above the detection limit of $<10^{2} \mathrm{CFU} / \mathrm{g}$ for all the samples.

The initial number of $E$. coli in the control, which is the sample without any additives, was $7.18 \mathrm{Log} \mathrm{CFU} / \mathrm{g}$ and was reduced to undetected level when $\mathrm{HP}$ of $600 \mathrm{MPa}$ was treated (Table 1). The number of E. coli was different in the sample by addition of food ingredients. The sample mixed with ethanol extracted garlic and leek showed a little lower initial number when compared with onion and ginger. After $300 \mathrm{MPa}$ of $\mathrm{HP}$, the numbers were slightly reduced but further increase of pressure to $450 \mathrm{MPa}$ decreased the number of E. coli rapidly. Similarly, the number of E. coli, Salmonella Typhimurium, and L. monocytogenes decreased only 1 Log cycles by $300 \mathrm{MPa}$ but 4-8 Log reduction was achieved by $450 \mathrm{MPa}$ in chicken breast fillet (Kruk et al., 2011). The result suggests that HP treatment with $300 \mathrm{MPa}$ is not enough to control these pathogens. There were no viable cells detected after HP of $600 \mathrm{MPa}$ regardless of treatments.

The initial load of the samples with irradiated food
Table 1. The combination effect of ethanol-extracted food ingredients and high pressure on Escherichia coli in ground pork (Log CFU/g)

\begin{tabular}{cllllll}
\hline \hline \multirow{2}{*}{$\begin{array}{c}\text { Irradiation } \\
\text { dose }(\mathrm{kGy})^{1)}\end{array}$} & Food & \multicolumn{5}{c}{ High pressure (MPa) } \\
\cline { 3 - 6 } & ingredient & 0.1 & 300 & 450 & 600 & \\
\hline \multirow{4}{*}{0} & Control & 7.18 & 6.41 & 3.46 & $\mathrm{ND}^{3)}$ & \\
\cline { 2 - 7 } & Garlic & $6.90^{\mathrm{a}}$ & $6.59^{\mathrm{b}}$ & $\mathrm{ND}^{\mathrm{c}}$ & $\mathrm{ND}^{\mathrm{c}}$ & 0.044 \\
& Leek & $6.67^{\mathrm{a}}$ & $6.29^{\mathrm{a}}$ & $1.79^{\mathrm{b}}$ & $\mathrm{ND}^{\mathrm{b}}$ & 0.562 \\
& Onion & $7.35^{\mathrm{a}}$ & $6.07^{\mathrm{a}}$ & $1.98^{\mathrm{b}}$ & $\mathrm{ND}^{\mathrm{c}}$ & 0.496 \\
& Ginger & $7.75^{\mathrm{a}}$ & $6.94^{\mathrm{a}}$ & $2.15^{\mathrm{b}}$ & $\mathrm{ND}^{\mathrm{c}}$ & 0.054 \\
\hline \multirow{4}{*}{5} & Control & 7.70 & 5.57 & 3.37 & $\mathrm{ND}^{2}$ & \\
\cline { 2 - 7 } & Garlic & $8.01^{\mathrm{a}}$ & $5.97^{\mathrm{b}}$ & $\mathrm{ND}^{\mathrm{c}}$ & $\mathrm{ND}^{\mathrm{c}}$ & 0.013 \\
& Leek & $8.10^{\mathrm{a}}$ & $5.87^{\mathrm{b}}$ & $2.71^{\mathrm{c}}$ & $\mathrm{ND}^{\mathrm{d}}$ & 0.109 \\
& Onion & $7.88^{\mathrm{a}}$ & $6.07^{\mathrm{b}}$ & $2.84^{\mathrm{c}}$ & $\mathrm{ND}^{\mathrm{d}}$ & 0.047 \\
& Ginger & $7.86^{\mathrm{a}}$ & $5.97^{\mathrm{b}}$ & $\mathrm{ND}^{\mathrm{c}}$ & $\mathrm{ND}^{\mathrm{c}}$ & 0.035 \\
\hline
\end{tabular}

${ }^{1)}$ Irradiation was applied for pasteurization of ethanol-extracted food ingredient.

${ }^{2}$ Standard errors of the mean $(\mathrm{n}=12)$

${ }^{3)}$ Viable cell was not detected with a detection limit at $<10^{1} \mathrm{CFU} / \mathrm{g}$.

${ }^{\mathrm{a}-\mathrm{d}}$ Values with different letters within the same row differ significantly $(p<0.05)$.

ingredients for $5 \mathrm{kGy}$ was higher than those with nonirradiated ones. A slightly but significantly higher reduction $(p<0.05)$ was achieved when $300 \mathrm{MPa}$ was treated when compared with the sample with non-irradiated additives. However, in general, there was no difference in pathogen reduction found at 450 and $600 \mathrm{MPa}$.

In the result from the sample treated with $450 \mathrm{MPa}$ of $\mathrm{HP}$, at least $1 \mathrm{Log}$ or higher pathogen reduction was observed by comparison of the samples between control and samples added with ethanol extracted food ingredients. It indicates the increase of efficiency in inactivation of pathogen by HP using combination with natural antimicrobial food ingredients. Among the food ingredients used, ethanol extracted garlic was the best in increase of efficiency of HP inactivation of E. coli. Yun et al. (2011) studied the effect of several food ingredients on radiation inactivation and reported that the most efficient ingredient against $E$. coli was ethanol extracted leek, followed by freeze-dried ginger and leek. The relative radiation sensitivity of ethanol extracted leek, freeze-dried ginger and leek, calculated as $\mathrm{D}_{10}$ of control/ $\mathrm{D}_{10}$ of sample mixed with food ingredients, were 3.89, 3.66, and 3.63, respectively.

Natural food ingredients have been known to possess antibacterial and antifungal activities, and contain the powerful sulfur and other numerous phenolic compounds (Benkeblia, 2004). The antimicrobial activities of phenolic compounds may involve multiple modes of action. 
Shan et al. (2007) suggested that phenolic compounds can degrade the cell wall, disrupt the cytoplasmic membrane, cause leakage of cellular components, change fatty acid and phospholipid constituents, influence the synthesis of DNA and RNA, and destroy protein translocation. Phenolic compounds also involve a sensitization of the phospholipid bilayer of the cell membrane, causing an increase in permeability and leakage of vital intercellular constituents (Kim et al., 1995) or impairment of bacterial enzymes (Wendakoon and Sakaguchi, 1995). Ponce et al. (1998) reported that high pressure produces and addition of nisin on gram-negative cells such as E. coli caused sub lethal injury in the outer membrane. Microbial cellular membrane is affected by high pressure, resulting in osmotic changes, lysis, alterations of nuclear materials, and other modifications which can result in cell death (Mackey et al., 1994).

Relatively higher reduction (1.5-2.5 Log reductions vs 0.5-2.0 Log reductions) of L. monocytogenes was achieved after $300 \mathrm{MPa}$ of HP treatment when compared with $E$. coli (Table 2). However, the result was reversed in the sample with $450 \mathrm{MPa}$ of HP, which showed that L. monocytogenes was slightly more resistant against HP. At 600 $\mathrm{MPa}$, the viable cells were not detected except for the ground pork with non-irradiated garlic.

Previously, Black et al. (2005) studied individual and combined effect of HP and nisin on bacteria contaminated in milk. The authors reported that the combination of HP and nisin enhanced the levels of inactivation for

Table 2. The combination effect of ethanol-extracted food ingredients and high pressure on Listeria monocytogenes in ground pork $(\log \mathrm{CFU} / \mathrm{g})$

\begin{tabular}{|c|c|c|c|c|c|c|}
\hline \multirow{2}{*}{$\begin{array}{l}\text { Irradiation } \\
\text { dose }(k G y)^{1)}\end{array}$} & \multirow{2}{*}{ Treatment } & \multicolumn{4}{|c|}{ High pressure (MPa) } & \multirow{2}{*}{$\mathrm{SEM}^{2)}$} \\
\hline & & 0.1 & 300 & 450 & 600 & \\
\hline \multirow{5}{*}{0} & Control & 7.40 & 5.30 & 2.90 & $\mathrm{ND}^{3)}$ & \\
\hline & Garlic & $7.15^{\mathrm{a}}$ & $4.95^{\mathrm{b}}$ & $2.94^{\mathrm{c}}$ & $1.49^{\mathrm{d}}$ & 0.406 \\
\hline & Leek & $7.25^{\mathrm{a}}$ & $3.83^{\mathrm{b}}$ & $2.59^{\mathrm{c}}$ & $\mathrm{ND}^{\mathrm{d}}$ & 0.282 \\
\hline & Onion & $7.37^{\mathrm{a}}$ & $4.95^{\mathrm{b}}$ & $3.00^{\mathrm{c}}$ & $\mathrm{ND}^{\mathrm{d}}$ & 0.072 \\
\hline & Ginger & $7.33^{\mathrm{a}}$ & $4.80^{\mathrm{b}}$ & $\mathrm{ND}^{\mathrm{c}}$ & $\mathrm{ND}^{\mathrm{c}}$ & 0.031 \\
\hline \multirow{5}{*}{5} & Control & 7.40 & 5.30 & 2.90 & ND & \\
\hline & Garlic & $7.43^{\mathrm{a}}$ & $5.65^{\mathrm{b}}$ & $\mathrm{ND}^{\mathrm{c}}$ & $\mathrm{ND}^{\mathrm{c}}$ & 0.022 \\
\hline & Leek & $7.41^{\mathrm{a}}$ & $5.32^{\mathrm{b}}$ & $3.55^{\mathrm{c}}$ & $\mathrm{ND}^{\mathrm{d}}$ & 0.029 \\
\hline & Onion & $7.46^{\mathrm{a}}$ & $5.81^{\mathrm{b}}$ & $\mathrm{ND}^{\mathrm{c}}$ & $\mathrm{ND}^{\mathrm{d}}$ & 0.038 \\
\hline & Ginger & $7.89^{\mathrm{a}}$ & $5.48^{\mathrm{b}}$ & 3.20 & $\mathrm{ND}^{\mathrm{d}}$ & 0.024 \\
\hline
\end{tabular}

${ }^{1)}$ Irradiation was applied for pasteurization of ethanol-extracted food ingredient.

${ }^{2)}$ Standard errors of the mean $(n=12)$

${ }^{3)}$ Viable cell was not detected with a detection limit at $<10^{1} \mathrm{CFU} / \mathrm{g}$.

${ }^{\mathrm{a}-\mathrm{d}}$ Values with different letters within the same row differ significantly $(p<0.05)$. both gram-negative and gram-positive bacteria. Usually, gram-negative bacteria are more sensitive to HP than gram-positive bacteria, probably due to the thicker cell wall of the former (Carlez et al., 1994). Low water activity protects cells against pressure, but microorganisms injured by HP are generally more sensitive to low water activity (Cheftel and Culioli, 1997). The combined treatment of enterocins and lactate-diacetate, with HP treatment eliminated microorganisms inoculated on cooked ham (Marcos et al., 2008). Evrendilek and Balasubramaniam (2011) also reported that HP processing combined with mint essential oil appeared to be a promising technique for preserving microbiologically-safe yogurt with no significant impacts to product quality. The decrease in intracellular ATP concentration in microorganisms such as E. coli and L. monocytogenes by the addition of essential oil is associated with the ability of essential oil to disrupt bacterial cell wall membranes and cause lysis (Lacroix et al., 2009; Rhayour et al., 2003).

The ratios of the reduction of pathogens in sample with food ingredients and control at 300 and $450 \mathrm{MPa}$ were calculated (Table 3). With minor exceptions, overall efficiency of HP treatment in inactivation of pathogens was increased. The $E$. coli reduction in ground pork with ethanol extracted garlic showed the highest (1.86) when HPtreated for $450 \mathrm{MPa}$. There was no evidence found for the advantage of pasteurization of ethanol extracted food ingredients. The present study demonstrates that the combination of antimicrobial food ingredient and HP treatment may improve the efficiency of sterilization in meat system.

Table 3. Pathogen inactivation efficiency of high pressure after combination of ethanol-extracted food ingredient

\begin{tabular}{ccccccc}
\hline \hline \multirow{2}{*}{ Pathogen } & \multirow{2}{*}{$\begin{array}{c}\text { Food } \\
\text { ingredients }\end{array}$} & \multicolumn{2}{c}{$300 \mathrm{MPa}^{1)}$} & & \multicolumn{2}{c}{$450 \mathrm{MPa}^{2)}$} \\
\cline { 3 - 4 } \cline { 6 - 7 } & & $0 \mathrm{kGy}$ & $5 \mathrm{kGy}$ & & $0 \mathrm{kGy}$ & $5 \mathrm{kGy}$ \\
\cline { 3 - 4 } Escheri- & Garlic & 0.40 & 0.96 & & 1.86 & 1.86 \\
chia coli & Oeek & 0.49 & 1.05 & & 1.31 & 1.25 \\
& Onion & 1.66 & 0.85 & & 1.44 & 1.17 \\
& Ginger & 1.05 & 0.89 & & 1.50 & 1.82 \\
\hline \multirow{2}{*}{ Listeria } & Garlic & 1.05 & 0.85 & & 0.94 & 1.65 \\
monocyto- & Leek & 1.63 & 1.00 & & 1.04 & 0.86 \\
genes & Onion & 1.15 & 0.79 & & 0.97 & 1.67 \\
& Ginger & 1.20 & 1.15 & & 1.63 & 1.04 \\
\hline
\end{tabular}

${ }^{1)}$ Calculated by the ratio of (Difference of viable cell in sample with food ingredient between $300 \mathrm{MPa}$ and $0.1 \mathrm{MPa}) /($ Difference of viable cell in control sample between $300 \mathrm{MPa}$ and $0.1 \mathrm{MPa}$ )

${ }^{2)}$ Calculated by the ratio of (Difference of viable cell in sample with food ingredient between $450 \mathrm{MPa}$ and $0.1 \mathrm{MPa}$ )/(Difference of viable cell in control sample between $450 \mathrm{MPa}$ and $0.1 \mathrm{MPa}$ ) 


\section{Acknowledgement}

This work was supported by a grant from the NextGeneration BioGreen 21 Program (No. PJ0081330), Rural Development Administration, Republic of Korea.

\section{References}

1. Benkeblia, N. (2004) Antimicrobial activity of essential oil extracts of various onions (Allium cepa) and garlic (Allium sativum). LWT Food Sci. Technol. 37, 263-268.

2. Black, E. P., Kelly, A. L., and Fitzgerald, G. F. (2005) The combined effect of high pressure and nisin on inactivation of microorganisms in milk. Innov. Food Sci. Emerg. Technol. 6, 286-292.

3. Caillet, S., Millette, M., Salmieri, S., and Lacroix, M. (2006) Combined effects of antimicrobial coating, modified atmosphere packaging, and gamma irradiation on Listeria innocua present in ready-to-use carrots (Daucus carota). $J$. Food Prot. 69, 80-85.

4. Carlez, A., Rosec, J. P., Richard, N., and Cheftel, J. C. (1994) Bacterial-Growth during Chilled Storage of PressureTreated Minced Meat. LWT Food Sci. Technol. 27, 48-54.

5. Cheftel, J. C. and Culioli, J. (1997) Effects of high pressure on meat: A review. Meat Sci. 46, 211-236.

6. Evrendilek, G. A. and Balasubramaniam, V. M. (2011) Inactivation of Listeria monocytogenes and Listeria innocua in yogurt drink applying combination of high pressure processing and mint essential oils. Food Control 22, 1435-1441.

7. Hoover, D. G., Metrick, C., Papineau, A. M., Farkas, D. F., and Knorr, D. (1989) Biological Effects of High HydrostaticPressure on Food Microorganisms. Food Technol. 43, 99107.

8. Kim, J. M., Marshall, M. R., Cornell, J. A., Preston, J. F., and Wei, C. I. (1995) Antibacterial activity of carvacrol, citral, and geraniol against Salmonella Typhimurium in culture medium and on fish cubes. J. Food Sci. 60, 1364-1368, 1374.

9. Kruk, Z. A., Yun, H., Rutley, D. L., Lee, E. J., Kim, Y. J., and Jo, C. (2011) The effect of high pressure on microbial population, meat quality and sensory characteristics of chicken breast fillet. Food Control 22, 6-12.

10. Lacroix, M., Caillet, S., and Shareck, F. (2009) Bacterial radiosensitization by using radiation processing in combination with essential oil: Mechanism of action. Radiat. Phys.
Chem. 78, 567-570.

11. Leistner, L. (2000) Basic aspects of food preservation by hurdle technology. Int. J. Food Microbiol. 55, 181-186.

12. Leistner, L. and Gorris, L. G. M. (1995) Food Preservation by Hurdle Technology. Trends Food Sci. Technol. 6, 41-46.

13. Mackey, B. M., Forestiere, K., Isaacs, N. S., Stenning, R., and Brooker, B. (1994) The Effect of high hydrostatic pressure on Salmonella Thompson and Listeria monocytogenes examined by electron microscopy. Lett. Appl. Microbiol. 19, 429-432.

14. Marcos, B., Jofré, A., Aymerich, T., Monfort, J. M., and Garriga, M. (2008) Combined effect of natural antimicrobials and high pressure processing to prevent Listeria monocytogenes growth after a cold chain break during storage of cooked ham. Food Control 19, 76-81.

15. Ponce, E., Pla, R., Sendra, E., Guamis, B., and Mor-Mur, M. (1998) Combined effect of nisin and high hydrostatic pressure on destruction of Listeria innocua and Escherichia coli in liquid whole egg. Int. J. Food Microbiol. 43, 15-19.

16. Prapaiwong, N., Wallace, R. K., and Arias, C. R. (2009) Bacterial loads and microbial composition in high pressure treated oysters during storage. Int. J. Food Microbiol. 131, 145-150.

17. Rastogi, N. K., Raghavarao, K. S. M. S., Balasubramaniam, V. M., Niranjan, K., and Knorr, D. (2007) Opportunities and challenges in high pressure processing of foods. Crit. Rev. Food Sci. 47, 69-112.

18. Rhayour, K., Bouchikhi, T., Tantaoui-Elaraki, A., Sendide, K., and Remmal, A. (2003) The mechanism of bactericidal action of oregano and clove essential oils and of their phenolic major components on Escherichia coli and Bacillus subtilis. J. Essent. Oil Res. 15, 286-292.

19. Shan, B., Cai, Y. Z., Brooks, J. D., and Corke, H. (2007) The in vitro antibacterial activity of dietary spice and medicinal herb extracts. Int. J. Food Microbiol. 117, 112-119.

20. Wendakoon, C. N. and Sakaguchi, M. (1995) Inhibition of amino acid decarboxylase activity of Enterobacter aerogenes by active components in spices. J. Food Prot. 58, 280283.

21. Yun, H., Lacroix, M., Jung, S., Kim, K., Lee, J. W., and Jo, C. (2011) Effect of several food ingredients on radiation inactivation of Escherichia coli and Listeria monocytogenes inoculated into ground pork. Radiat. Phys. Chem. 80, 994997.

(Received 2011.9.18/Revised 2011.11.6/Accepted 2011.11.15) 